\section{Novel Spectroscopy in Winterthur}

As scientific balance to the more administrative meetings of the Associate Members with the Executive Committee and ACAPPI in Winterthur, a Symposium on Novel Spectroscopy was held on 27 March. It opened with a short historical review by G. Harbeke (RCA, Zürich) who reminded his listeners of the long way spectroscopy had come since Newton first studied the visible spectrum produced by a prism in 1672 . Indeed from the programme, one might be led to think that now any measurement that shows a variation with physical properties seems to warrant the term spectroscopy. This may perhaps be justified in the sense that waves are so often in question, but the original meaning is progressively becoming rather blurred.

Spectroscopy in the traditional sense is nevertheless still a powerful tool. Both the opening of the EM frequency band from radio to gamma-rays practically continuously and the availability of lasers over a wide range of selected frequencies have stimulated a dramatic surge in activity since the 1950 s. The performance of a spectrometer can be characterised by its resolution $(R)$, efficiency of energy collection and contrast (C) not all of which can be optimised at the same time. In the visible range $R=$ $\lambda / \triangle \lambda$ can attain $10^{5}$ for grating instruments, and with lasers and modern holographic gratings, $C$ can be $10^{9}$ at $5 \AA$ from the line centre and $10^{11}$ at $20 \AA$.

An enormous amount of information has been amassed on silicon using spectroscopic techniques since the first conclusions on its band structure were obtained from its transmission spectrum in 1958. These were then supplemented by reflection measurements to provide a detailed picture of its intrinsic electronic states. For extrinsic states, one has recourse to IR or far - IR spectroscopy using interferometry - the same in principle as devised by Michelson, but made much more powerful by high precision optics and the availability of fast com-

Table - Characteristics of modern lasers

\begin{tabular}{|c|c|c|c|c|}
\hline Laser System & $\begin{array}{c}\text { Duration, } \\
\text { ps }\end{array}$ & $\begin{array}{l}\text { Tuning, } \\
\mathrm{cm}^{-1}\end{array}$ & $\begin{array}{c}\text { Energy, } \\
\mathrm{J}\end{array}$ & $\begin{array}{c}\text { Rep. Rate, } \\
\mathrm{Hz}\end{array}$ \\
\hline Nd: glass & $1-8$ & - & $10^{-4}\left(10^{-2}\right)$ & $1(0.1)$ \\
\hline Nd: YAG & $20-100$ & - & $10^{-3}\left(10^{-1}\right)$ & $10(5)$ \\
\hline$c w$ - Nd: YAG & 100 & - & $10^{-8}$ & $10^{8}$ \\
\hline $\mathrm{cW}-\mathrm{Ar}$ & 100 & - & $10^{-8}$ & $10^{8}$ \\
\hline Dye laser (passive, cw - Argon) & $0.1-2$ & $0-500$ & $10^{-10}\left(10^{-3}\right)$ & $10^{8}(5)$ \\
\hline Dye laser (synchronous coupling) & $1-20$ & 5000 & $10^{-10}\left(10^{-4}\right)$ & $10^{8}\left(10^{2}\right)$ \\
\hline
\end{tabular}

the potential of this source, it is surprising how slowly industry in Europe has reacted, in contrast to the USA where industrial participation in the setting up of big facilities has been strong. Demonstrating the versability of synchrotron radiation as a tool, Y. Petroff (LURE, Orsay) spoke of $X$-ray microscopy with a resolution of $1 \mu \mathrm{m}$; Extended X-ray Absorption Fine Structure (EXAFS) with a time resolution down to $1 \mathrm{~ms}$; photon-electron spectroscopy for surface studies; X-ray elastic scattering of monochromatic beams (produced by crystal monochromators) which has reduced by up to six orders of magnitude the time needed to collect data on large molecular structures and has opened the possibility of making in vivo time resolved measurements of biological processes. An account of some of the research at the BESSY storage ring in Berlin will be given in a coming issue of Europhysics News.

The discovery of Raman lines weak lines produced by the interaction between an incident beam and the molecular states - goes back to 1928 , whilst enhanced Raman scattering $\left(10^{6}\right.$ stronger), observed from certain molecules adsorbed onto a metallic surface, came to light only in 1974. Such a spectacular effect, seen first with pyridine on silver, could not fail to attract a great deal of attention and it is now being developed into an effective analytical tool for surface studies. At least two mechanisms contribute to the enhancement A. Wokaun (ETH, Zürich) explained. The major part depends on surface roughness which leads to plasmon resonances and a large field amplification localised round protrusions through the lightning rod effect. This can give an enhancement of around $10^{4}$ which implies that we have to account for a further two orders of magnitude. These come from mechanisms such as electron-hole pair formation and intramolecular electronic and charge transfer resonances at specific adsorption sites.

The effect can be applied to the study in detail of the interactions associated with adsorbed molecules on a metallic surface, distinguishing between those that are physi- and those that are chemisorbed. The build up of layers of molecules can be followed and changes in the bonding geometry. Such processes are of particular importance for research on catalytic induced chemical reactions which are basic to so much industrial chemical manufacture.

The secret of a lot of modern spectroscopy seems to lie in doing apparently familiar things superbly well. Measuring the electrical resistance of a junction 
when a few volts are applied across it may not seem very promising, but first $P$. Wyder (FOM and University of Nijmegen) showed that the information that can be extracted can be surprisingly rich.

With point contact spectroscopy, the novelty lies in measuring the deviations from Ohm's law in the contact resistance between a fine point (typically 0.5 $\mu \mathrm{m}$ radius) and the surface of interest, which is cooled to say $1.2 \mathrm{~K}$. Controlling the inter-electrode distance to better than $10^{-2} \mu \mathrm{m}$ allows contact to be made with one of the "mountains" rising from the point to give a contact radius (a) measured in $\AA$ and a current density in $\mathrm{MA} / \mathrm{cm}^{2}$. Whereas on the macroscopic scale, Maxwell derived the contact resistance $R$ as being inversely proportional to $a$, Sharvin deduced that when the electron mean free path was large compared with the linear dimensions, $\mathrm{R} \propto$ $1 / a^{2}$. In practice, the relation between $R$ and $a$ is somewhere between $1 / a$ and $1 / a^{2}$ and is a function of the mean free path. Consequently there is a non-linear dependency of $R$ on the applied voltage $V$ and it is the derivative $d R / d V$ that contains so much information. Plotting this function allows one to obtain directly the spectral distribution of the electronphonon interaction and from comparisons with data from other spectroscopic measurements, the coupling strengths of different modes can be separated out. Besides phonons, however, other scattering agents can be examined by point contact spectroscopy which has the very unusual characteristic of performing, in effect, surface analysis from the inside. Ballistic observations can be made for example of the reflexion of conduction electrons from surfaces, or their reflexion as "holes" - the so-called Andreev process - if the sample becomes superconducting.

Break the contact and we are in the domain of the scanning tunelling microscope for which $\mathrm{G}$. Binnig and $\mathrm{H}$. Rohrer (IBM, Zürich) have been awarded the EPS 1984 Hewlett-Packard Europhysics Prize and a number of other distinctions. The principle as already outlined in Europhysics News (February, 1984) rests on the very strong dependence of tunnelling current on the distance $s$ between a fine metal tip and the surface to be studied. To a first approximation, the current through a vacuum tunnel barrier of width $s$ is given by:

$$
J \propto \exp \left(-A \phi^{1 / 2} s\right)
$$

where $A$ is a constant $\approx 1 \AA^{-1}(\mathrm{eV})^{1 / 2}$

$\phi$ is the barrier height (or average work function, of the electrodes typically a few eV). This implies a current depen-

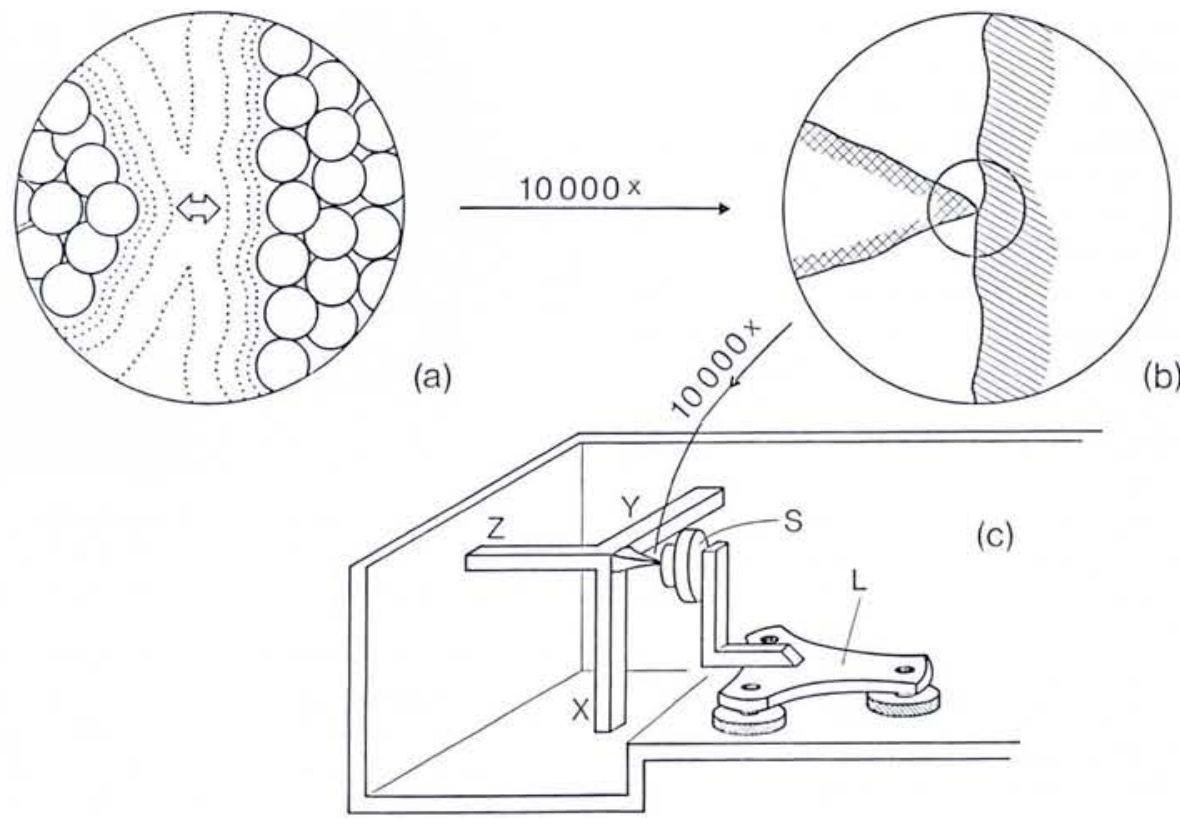

Schematic of the scanning tunnelling microscope (a) shows apex of the tip (left) and surface (right) at a magnification of about $10^{8}$. The solid circles indicate atoms, the dotted lines electron density contours; (c) Piezodrives $X, Y, Z$ of the tunnel tip (length of each leg about $5 \mathrm{~cm}$ ) at left and "louse" $L$ (electrostatic "motor") for rough positioning ( $\mu \mathrm{m}$ to $\mathrm{cm}$ range) of sample $S$.

dency on $s$ of an order of magnitude per $\AA$.

In the microscope of Binnig and Rohrer, as the surface under study is scanned, the tip is maintained at a constant distance $s$ (typically 4-6 $\AA$ ) set by

adjusting the current (typically $1-10 n \mathrm{~A}$ ), the position of the tip being controlled by the voltages applied to three mutually orthogonal drives.

The tip electrode is formed by grinding a metal rod which leaves fine protruding

\section{THE PENNSYLVANIA STATE UNIVERSITY}

\section{EXPERIMENTAL SYNCHROTRON RADIATION SURFACE PHYSICS}

The Departement of Physics is seeking candidates for a tenuretrack position at the Assistant or Associate Professor level in experimental synchrotron radiation surface physics starting in the 1984-85 academic year. Candidates should have an established record of research accomplishments in this area. It is expected that the candidate will maintain strong affiliation with one or more of the national light source facilities. Opportunities exist for collaboration with active experimental and theoretical surface physics programs at Penn State in atom-surface scattering, photon, electron and ion emission spectroscopies, as well as other areas of surface, condensed matter and materials research. A competitive salary and start-up funds will be available. A successful candidate will be expected to establish a vigorous and creative research program capable of independent external funding. A commitment to and aptitude for teaching of undergraduate and graduate students is also essential.

Interest persons should send curriculum vitae and names of four references to:

Professor Gerald A. Smith, Head, Department of Physics,

Box A, 104 Davey Laboratory, The Pennsylvania State University, University Park, PA 16802

by July 1, 1984 or until a suitable applicant is identified.

An affirmative action/equal opportunity employer. 
points, the most extreme of which becomes the active electrode. Lateral resolution can then be improved by lightly making contact to produce a sort of spot weld and then withdrawing or by applying a few volts for $1 / 2$ hour. In this way, single atomic steps on metal and semiconductor surfaces and, more recently, single adatoms could be resolved within a lateral displacement of a few $\AA$.

Crucial to the success of the microscope is the manner in which the electrodes are mounted and then isolated from outside influences. In the present design, the electrodes and piezodrives are rigidly mounted on a quartz glass cage (low thermal expansion) which is suspended in vacuum via a two-stage spring system. Remaining vibrations are attenuated by special rubber connectors and by contactless eddy-current dampers. The sample, rigidly held on a piezoelectric plate, can be displaced in steps (of say $100 \AA$ ) by expanding or contracting the plate while permutating the clamping voltages that lock the feet (on which the plate rests) to the solid base. The tip is then positioned relative to the surface under study by piezo-electric drives with a typical sensitivity of $2 \AA / \mathrm{N}$.

By now, the scanning tunnelling microscope has ceased to be just an electro-mechanical wonder and has become a recognised instrument for surface studies. What are essentially traced during a scan are the contours of constant wave-function overlap within an energy window determined by the applied voltage. This is not the same as a direct image of the surface topography although with clean metal surfaces the relation is close. Because the method is energy selective (and can be made spin selective with a magnetised tip), it can give information on the chemistry of the surface with a resolution that has reached $0.05 \AA$ vertically and $2 \AA$ laterally.

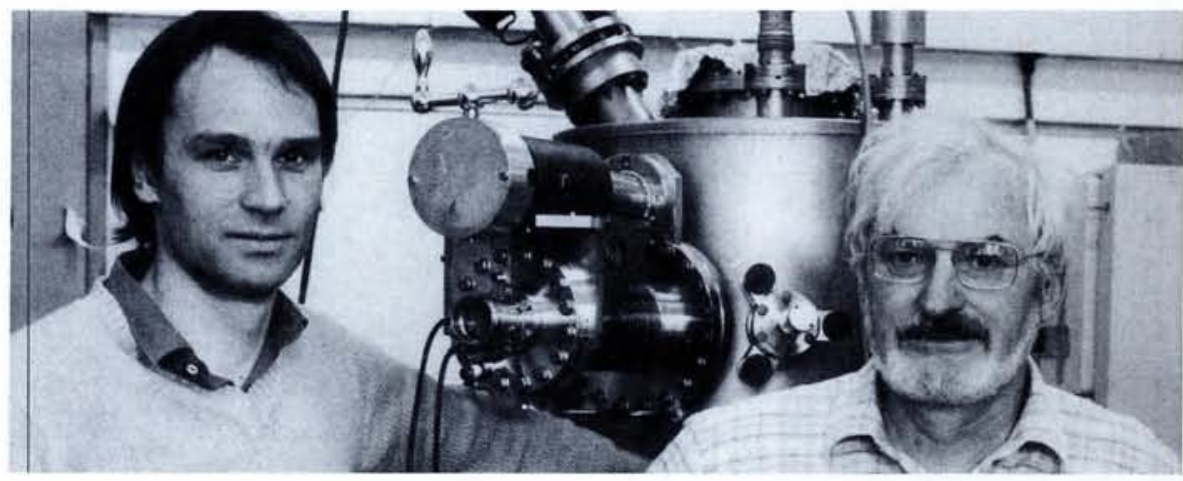

Gerd Binnig (left) and Heinrich Rohrer of the IBM Zürich Research Laboratory with their scanning tunnelling microscope for the building of which they have been awarded the 1984 Hewlett-Packard Europhysics Prize. This will be presented in Prague during the 6th EPS General Conference.

JET, the Joint European Torus located near Abingdon in England, was officially opened by H.M. Queen Elizabeth II on 9 A pril 1984. The ceremony consisted of actuating the massive door separating the assembly hall from the machine hall and unveiling a commemorative plaque. JET, a joint undertaking of the European Communities (EC) is the most powerful tokamak operating today. In the photograph taken during the Queen's address can be seen (nearest camera) E. Davignon, Vice-president of the EC Commission, and at the end of the same row, J. Teillac, Chairman of the JET Council. Extreme right is H.-O. Wüster, Director of the Project, Madame Thorn, Gaston Thorn, President of the EC Commission and Francois Mitterrand, attending in his capacity as President of the EC Council of Ministers. Since the first discharge in June 1983, JET has been worked up to its nominal design current of 3MA with a flat top of $10 \mathrm{~s}$, an energy confinement time of $0.25 \mathrm{~s}$ and a plasma temperature of $20 \mathrm{MK}$.

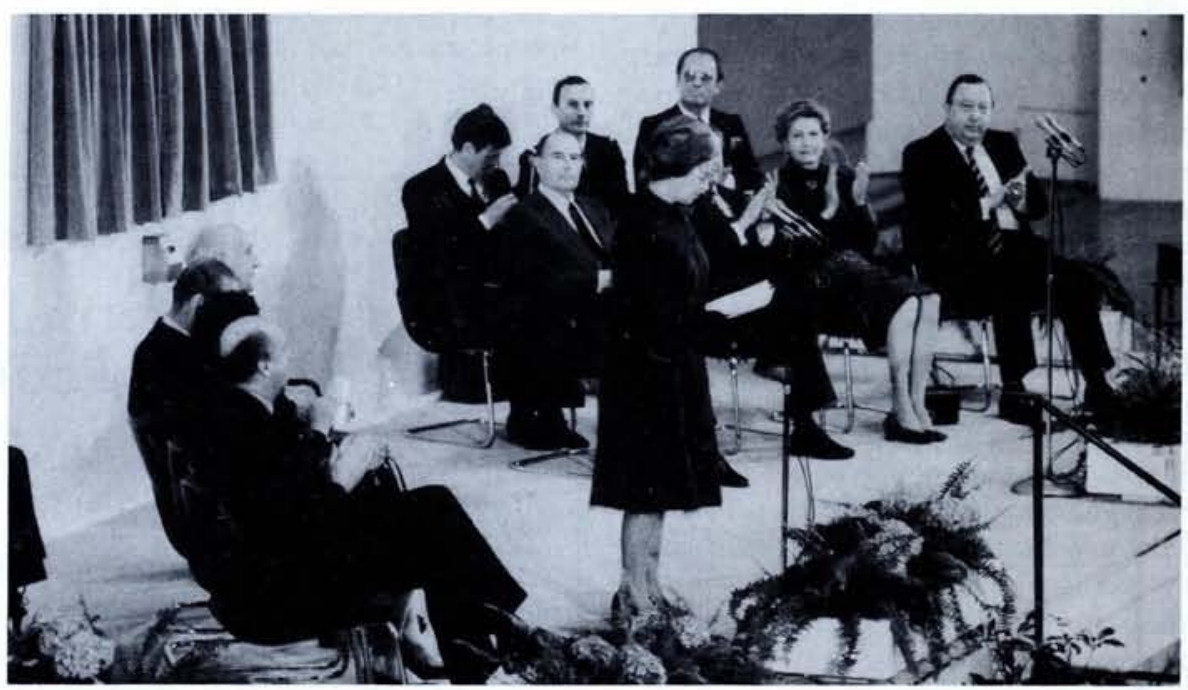

EPS Divisions, Sections and Group

Astronomy and Astrophysics Division Solar Physics Section

Atomic and Molecular Physics Division Atomic Spectroscopy Section Chemical Physics

Electronic and Atomic Collisions

Molecular Physics

Computational Physics Group

Condensed Matter Division

Liquids Section

Low Temperature Physics Section

Macromolecular Physics

Magnetism

Metal Physics

Setal Physics

Semiconductors and Insu

High Energy \& Particle Physics Division

Nuclear Physics Division

Optics Division

Plasma Physics Division

Quantum Electronics Division
Europhysics News is the official journal of the European Physical Society which comprises 29 National Societies, Academies and Group, over 3000 Individual Memties, Academies and Group, over 3000 Individual MemEPS are the General Meeting, Council and an elected Executive Committee responsible for detailed policy. EPS promotes the collaboration of physicists throughout Europe, organising and harmonising conferences and publications, improving physics education, encouraging physics applications, awarding scholarships to sponsored schools in Erice. EPS publishes in addition to EN, Europhysics Conference Abstracts, E. Ed. News and, in collaboration with The Institute of Physics (UK). the European Joumal of Physics. Individual Members receive $E N$ free of charge (price to institutions: Sw.Fr. 90.-/a), rebates on the price of many publications and on conference fees. Annual EPS membership fee for Individual Members belonging to an EPS member society is: Sw.Fr. 40.-; independent members: Sw.Fr. 120.-: members of a Collaborating Society, e.g. the American Physical Society: Sw.Fr. 50.- (\$25).

\section{Editor: E.N. Shaw}

Meetings Compilation: W.S. Newman

Editorial Board

K. Appert, A. Baratoff, B. Jacrot,

G.R. Macleod, A. Maeder, J. Muller

Editorial and Advertising Office at the EPS Secretariat

Address: EUROPEAN PHYSICAL SOCIETY

P.O. Box 69 ,

CH-1213 Petit-Lancy 2

Switzerland

Telephone: Geneva (22) 931130

Telex : $\mathbf{4 2 3} \mathbf{4 5 5}$ dema ch

Cables: europhys genève

Printed by: Pfirter frères sa

CH-1213 Petit-Lancy/Switzerland 